Portland State University

PDXScholar

6-1-1993

\title{
The Relationship Between Precipitation and Temperature Over the Contiguous United States
}

Weining Zhao

Oregon Graduate Institute of Science and Technology

M. A. K. Khalil

Portland State University, aslamk@pdx.edu

Follow this and additional works at: https://pdxscholar.library.pdx.edu/phy_fac

Part of the Physics Commons

Let us know how access to this document benefits you.

Citation Details

Zhao, Weining, M. A. K. Khalil, 1993: The Relationship between Precipitation and Temperature over the Contiguous United States. J. Climate, 6, 1232-1236.

This Article is brought to you for free and open access. It has been accepted for inclusion in Physics Faculty Publications and Presentations by an authorized administrator of PDXScholar. Please contact us if we can make this document more accessible: pdxscholar@pdx.edu. 


\title{
The Relationship between Precipitation and Temperature over the Contiguous United States
}

\author{
WEINING ZHAO AND M. A. K. KhaLIL \\ Global Change Research Center, Department of Environmental Science and Engineering, \\ Oregon Graduate Institute of Science and Technology. Beaverton, Oregon
}

29 July 1991 and 10 August 1992

\begin{abstract}
The correlation between monthly total precipitation and monthly mean temperature over the 80-year period from 1905 to 1984 at nearly 1000 stations in the contiguous United States was calculated and analyzed. Both local and field significances were tested by using statistical methods. Areas of both negative and positive precipitation-temperature correlations were found. Over most of the United States, summer precipitation and temperature were negatively correlated, which indicates that warm summers tended to be dryer. This is particularly true in the central and southern Great Plains. The area south of the Great Lakes covering the eastern portion of the Corn Belt was the only major area where a significant positive correlation was found in winter.
\end{abstract}

\section{Introduction}

Several authors have explored the direct association of precipitation and temperature over the United States, and evidence has been reported that there is a relationship between them (see Blair 1931; Hamrick and Martin 1941; Madden and Williams 1978; Crutcher 1978; Van den Dool 1988 and 1989). Hamrick and Martin (1941) compared summer rainfall and summer temperature records from 1898 to 1938 in Kansas City, Missouri. Their curves of ten-year means of precipitation and temperature show a distinct negative correlation between rainfall and temperature during the summer months throughout the entire period. Madden and Williams (1978) also indicated that dryer summers in the central United States were usually warmer. They calculated the correlations of seasonal total precipitation and mean temperature for summer and winter, based on the 64-year time series from 1897 to 1963 at 65 stations across North America. In a more comprehensive study, Crutcher (1978) has further defined these relationships by computing correlations between temperature and total precipitation within the United States for each month of the year; 40 and 102 stations were used for the periods 1906-1948 and 1949-1970, respectively. In a recent study, Van den Dool (1988 and 1989) published an atlas containing maps illustrating the relationship between precipitation and temperature. Van den Dool used 57 years (1931-

Corresponding author address: Prof. M. A. K. Khalil, Global Change Research Center, Department of Environmental Science and Engineering, Oregon Graduate Institute, 19600 N.W. von Neumann Drive, Beaverton, OR 97006.
1987) of monthly precipitation and temperature data at 344 United States Climate Divisions.

Here, we intend to complement earlier studies of the relationship between precipitation and temperature by examining the correlation of these two climatic elements over the contiguous United States. We have used a dataset covering longer time period and more sites than in any previous study. Modern statistical methods were used to test the statistical significance of our results.

\section{Data description}

Data of monthly total precipitation and monthly mean temperature employed in this analysis are from the United States Historical Climatology Network (HCN) obtained from the Carbon Dioxide Information Analysis Center, Oak Ridge, Tennessee (see Quinlan et al. 1987). The data are from 1219 stations with relatively uniform distribution in the contiguous United States. The major advantage of this database is that the stations in the network had few instrument and site changes over the length of the data and were located in areas with low population to avoid substantial influence of man-made changes of local environments (Karl et al. 1988). In addition to these selection criteria, the raw data were subjected to an exhaustive set of the data reduction techniques and the quality control procedures that adjust for documented discontinuities including the time of observation, station and instrument changes, missing data, and relative inhomogeneities thus eliminating many potential biases (Karl et al. 1986; Karl and Williams 1987; Quinlan et al. 1987).

A total of 949 stations have complete monthly mean 
temperature and total monthly precipitation records in the 80-year period from 1905-1984. Another 36 stations had complete records in some seasons but not through the entire year. These 985 stations were included in this analysis.

\section{Significance tests}

Correlation coefficients are calculated for each station and each month and the spatial variability of precipitation-temperature relationships is illustrated in the contour maps (Fig. 1). The statistical tests are conducted for both the local and field significance of the correlations.

The test for local significance refers to the strength of correlations for individual stations. Since temporal dependence exists in the temperature and precipitation data, the effective number of degrees of freedom (EDOF) is not the same as the number of data that enter into the calculation of the correlations. Davis (1976) presents a method of estimating the EDOF as

$$
\mathrm{EDOF}=\frac{N \Delta t}{\tau}
$$

where

$$
\tau=\left(1+2 \sum_{i=1}^{n} C_{P P}(i \Delta t) C_{T T}(i \Delta t)\right) \Delta t
$$

and $C_{P P}$ and $C_{T T}$ are the autocorrelation coefficients of the time series of precipitation and temperature, respectively. The $\tau$ is the integral time scale and determines the time period required to gain a new degree of freedom in the estimation of the correlation. This method has been implemented in several works (e.g., Chen 1982; Karl et al. 1984). To limit the sampling error of autocorrelations, the maximum lag was chosen as the half size of the sample number, that is, $n=40$ in Eq. (2). We applied Davis' method to estimate the EDOF at each station and for each month. The correlation was tested at the 5\% significance level at each station based on its EDOF.

The test for field or collective significance addresses the question as to whether the number of statistically significant local correlations is higher than can be expected by chance. Livezey and Chen (1983) discuss and present the general concepts and motivation for field-significance testing. The Monte Carlo technique was employed to implement the field-significance test. First, one of two time series (in this case, temperature) at a station is randomly reordered, and a correlation coefficient is calculated between it and precipitation data. This correlation coefficient is then tested for local significance. This is repeated for all stations with the same randomized temperature order for each trial. The number of stations that have precipitation-temperature correlations locally significant at the $5 \%$ level is then obtained for the trial. This procedure is repeated sufficiently (a thousand times in this study) with each trial having different randomized order. Thus, we can obtain the frequency distribution of the numbers of locally significant stations. The field significance at the $5 \%$ level is determined by the number of locally significant stations at $95 \%$ cumulative frequency. Finally, the actual number of locally significant stations is compared with this $5 \%$ significant level to determine the field significance.

\section{Geographic patterns}

Figure 1 illustrates the geographic patterns of precipitation-temperature correlations for each month. The maps show contours of the correlation coefficients between monthly total precipitation and monthly mean temperature. The calculation of EDOFs has showed that more than $95 \%$ of stations have EDOF values over 60 for all the months. The absolute value of the correlation coefficient at the $5 \%$ significance level for $\mathrm{EDOF}=60$ is 0.25 . This value was chosen to define the borders (dashed line) of the significant areas in the contour maps (Fig. 1). The stations with EDOFs less than 60 have been carefully examined. Only two stations were found to have the significant correlations based on EDOF $=60$ but insignificant correlations based on their local EDOFs. The Monte Carlo tests for the field significance indicated that in all 12 months there were more stations with local, significant, positive or negative correlations than would be expected by chance at the 5\% level; and summer months were more significant than winter months.

Geographic patterns of precipitation-temperature correlations varied from month to month, with the statistically significant areas covering almost all of the contiguous United States in some months, such as June, and only a few scattered in small areas in other months, such as February. However, in most of the areas of significant correlations, precipitation and temperature tended to be negatively correlated-warmer than normal temperatures usually resulted in dryer conditions and colder periods were likely to be wetter. During summer (June, July, and August), this significant inverse relationship between precipitation and temperature persisted over most of the contiguous United States. The warmer-dryer or colder-wetter relationship, therefore, was the predominant summer pattern in the continent, a feature that has been shown before (Madden and Williams 1978; Crutcher 1978; Van den Dool 1988 and 1989). This area was at its largest size in June and narrowed through July and August, while the strongest negative correlations remained through the entire summer season in the central and southern Great Plains.

Both locally significant, negative and positive correlation areas were found in winter months (December, 

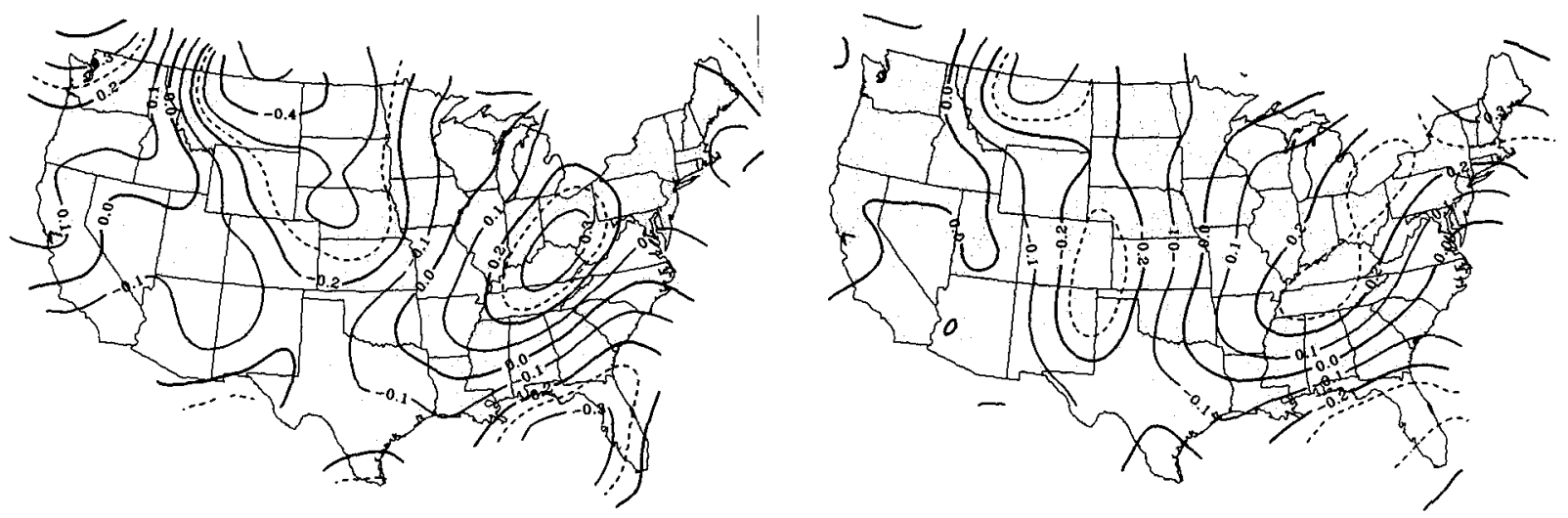

January

February
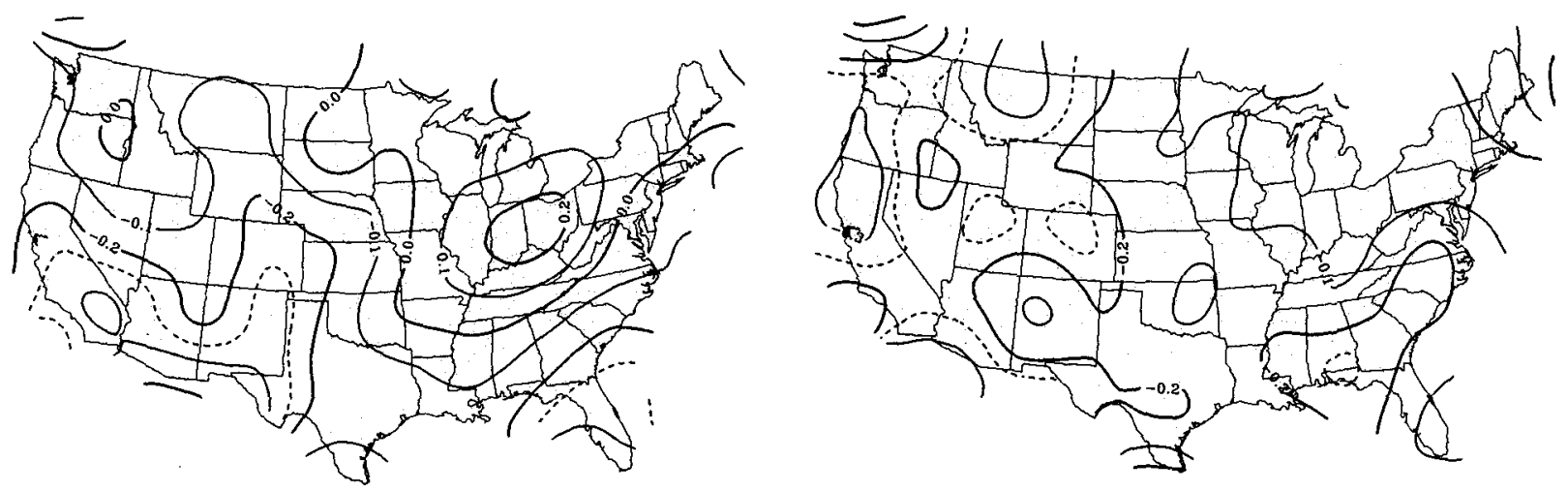

March

April
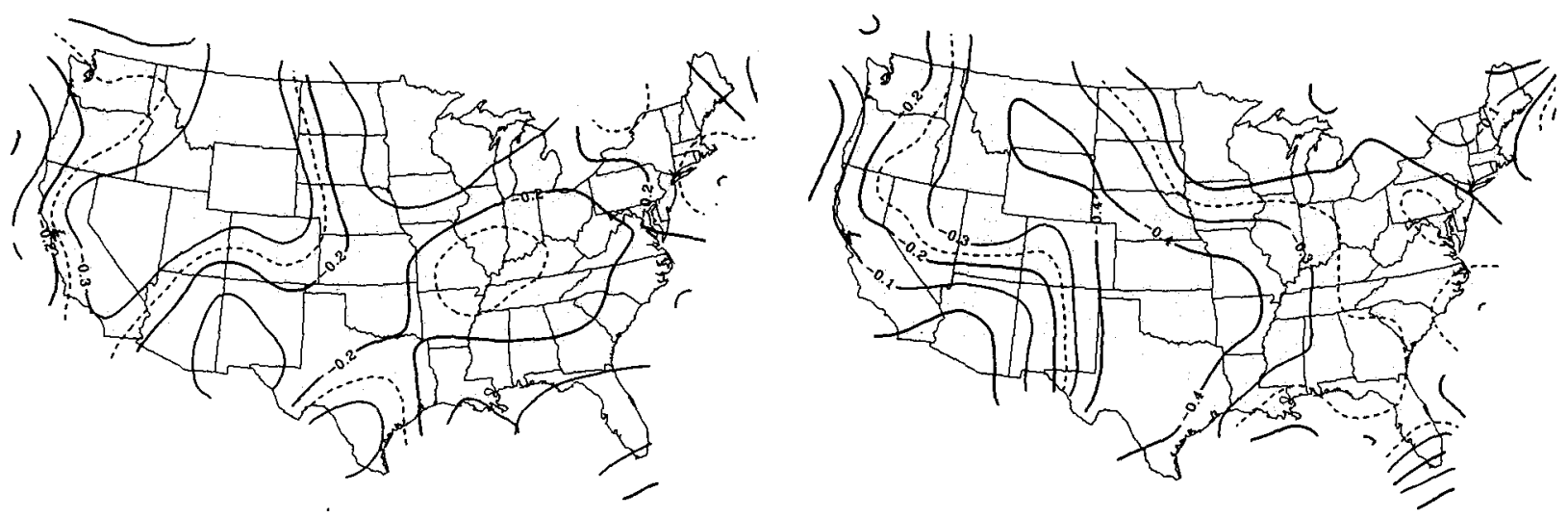

May

June

FIG. 1. Contours of correlation coefficients between precipitation and temperature for each month. The correlations are calculated for the data of monthly total precipitation and monthly mean temperature of each month over the period of 1905-1984. Dashed lines are the $5 \%$ significance level for $\mathrm{EDOF}=60$.

January, and February). Sizable areas with significant positive correlation existed mainly in winter. These scattered areas, including parts of the Pacific Northwest, New England, and a large area south of the Great Lakes, are where warmer winters were wetter and colder winters dryer. One may notice that the area south of the Great Lakes, shown in the maps of three winter months, is the largest area where the significant positive precipitation-temperature correlation existed.

As transition seasons between winter and summer, spring and autumn generally did not show very strong precipitation-temperature correlations; the only significant areas were mainly in the middle and western United States. 

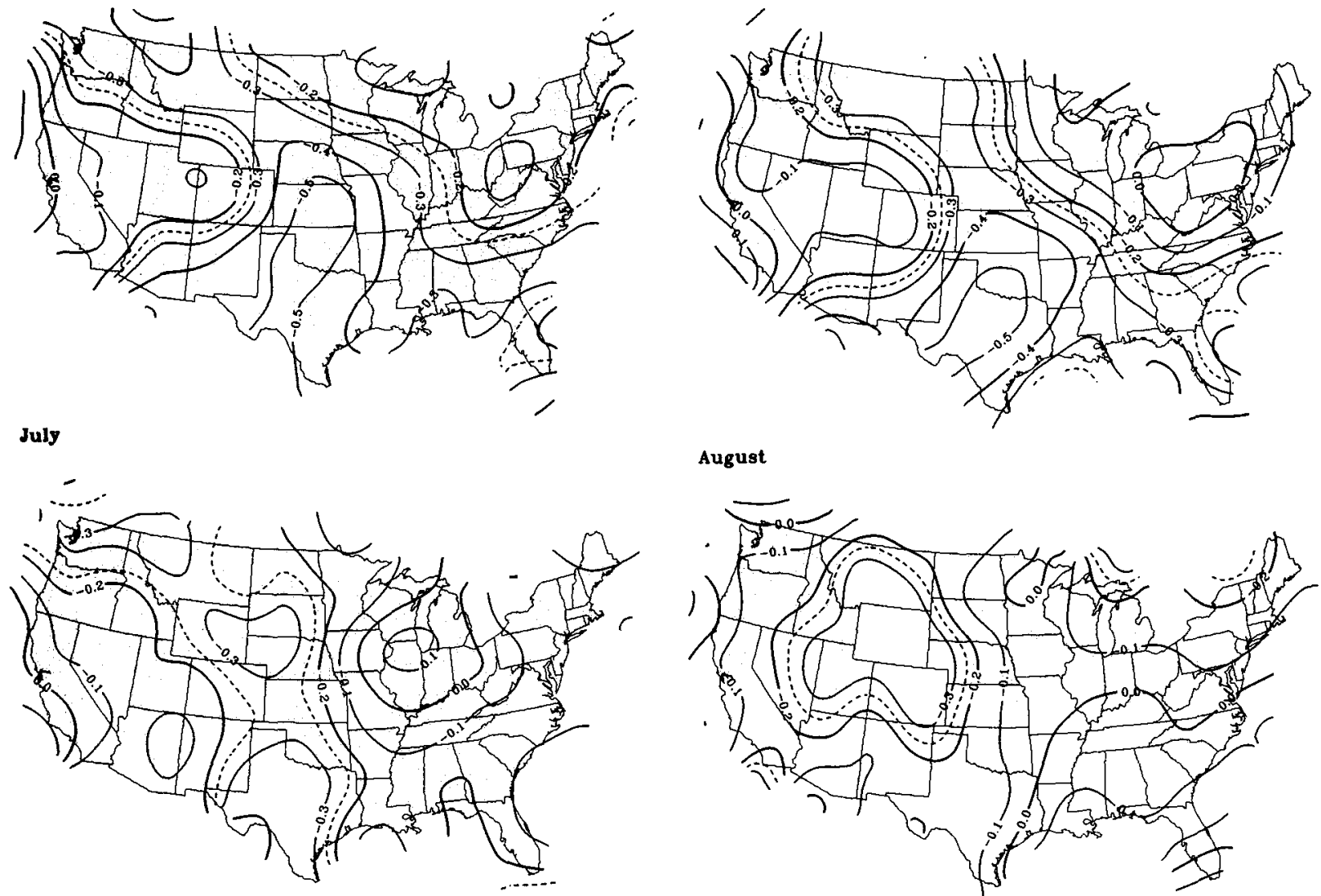

August

September

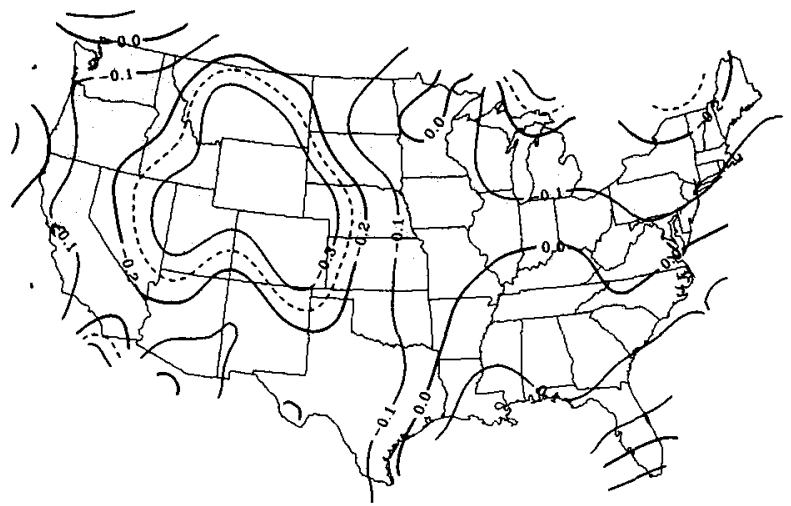

October

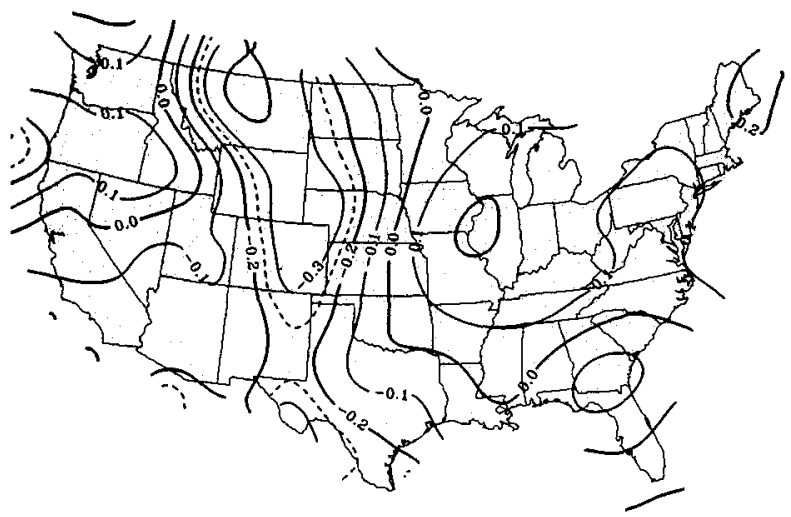

November

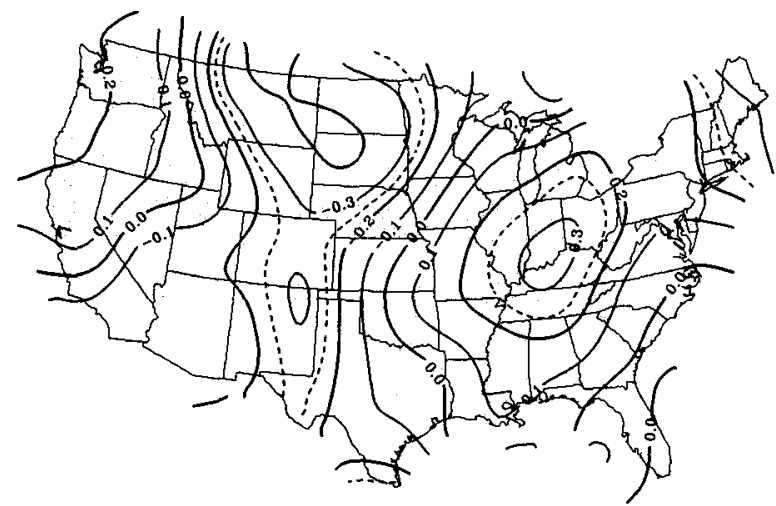

December

FIG. 1. (Continued)

\section{Central Great Plains in summer}

The central United States is the area where the statistically significant negative precipitation-temperature relationship occurs in summer. This area is one of the main agricultural regions of the United States. In the central and southern Great Plains, the negative correlation is particularly strong. We chose the stations within $32^{\circ} \mathrm{N}-42^{\circ} \mathrm{N}$ latitude and $95^{\circ} \mathrm{W}-105^{\circ} \mathrm{W}$ lon- gitude (including Kansas, Oklahoma, most of Nebraska, the eastern reach of Colorado and New Mexico, and northern Texas) and calculated the regional means of summer precipitation and temperature by averaging monthly total precipitation and monthly mean temperature, respectively, over 116 stations within this area. Out of 80 years of the record, 28 years showed that the wa.mer-than-average summers were abnormally dryer, and 29 years had abnormally colder and 
wetter summers; that is, $71 \%$ of the years had the inverse relationship between precipitation and temperature. The correlation coefficient between precipitation and temperature is approximately -0.75 . The plot of precipitation deviation versus temperature deviation is shown in Fig. 2 with the linear regression line and the $95 \%$ confidence band.

\section{Conclusions}

Examination of the correlation between precipitation and temperature revealed some significant features. Over most of the United States summer precipitation and temperature tended to be negatively correlated, with the greatest negative correlation in the central and southern Great Plains. Significant positive correlations mainly occurred in winter in the area south of the Great Lakes, including most of Indiana, part of Illinois, Ohio, Kentucky, and Tennessee. This area covers the eastern portion of the United States Corn Belt. In the eastern Rocky Mountains area, negative correlations persisted throughout the entire year; while neither coasts showed strong correlation throughout the entire year. A strong positive correlation was found only in the large area south of the Great Lakes. These features as well as temperature-precipitation relationship in each state are discussed in more detail by Zhao (1991).

The relationships that have been observed may be explained by several physically different mechanisms. Such correlations may occur because of changes in cloud cover or changes in precipitation and the consequent changes in the heat balance of the regions under consideration.

It is not known whether the correlations found in the data of the last 100 years are analogous to what

Central Great Plains $(r=-0.75)$

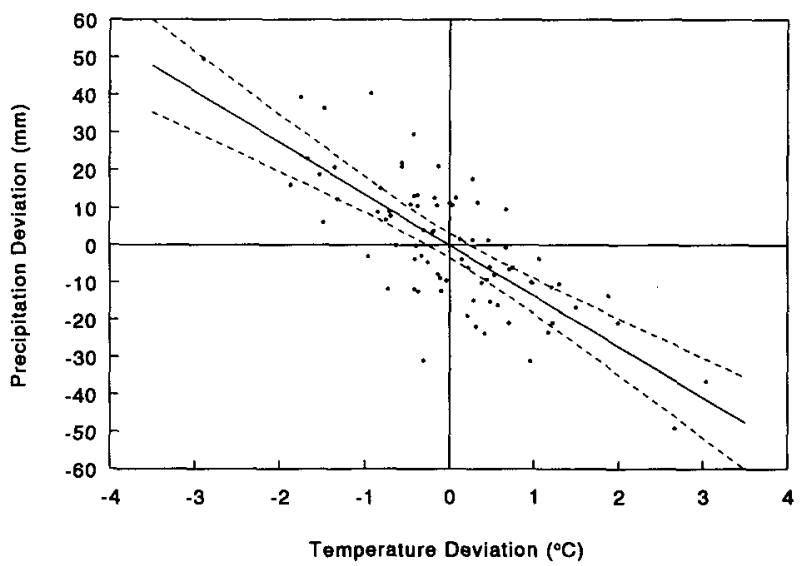

FIG. 2. Deviations of monthly total precipitation versus deviations of winter monthly mean temperature in the Central Great Plains in summer. The dashed line is the linear-regression fitting and its $95 \%$ confidence band. The $R$ is the correlation coefficient between precipitation and temperature. may happen if the earth warms from increasing levels of trace gases. This possibility, however, is an important reason for careful documentation of the observed correlations and for further studies on the mechanisms that control these correlations.

Acknowledgments. We thank R. M. Mackay, F. Moraes, M. J. Shearer, Y. Lu, J. F. Holmes, W. M. Jarrell, R. A. Rasmussen, and M. Riches for discussions and suggestions. We thank Dr. Robert E. Livezey for his many constructive comments, his ideas that made us appreciate the subtleties of our findings and for choosing tough but knowledgeable reviewers. This research was supported in part by a grant from the Department of Energy (DE-FG06-85ER60313). Additional support was provided by the Andarz Co.

\section{REFERENCES}

Blair, T. A., 1931: Relations between winter temperature and precipitation. Mon. Wea. Rev., 59, 34-55.

Chen, W. Y., 1982: Fluctuations in Northern Hemisphere 700-mb height field associated with southern oscillation. Mon. Wea. Rev. 23, 808-823.

Crutcher, H. L., 1978: Temperature and precipitation correlations within the United States. NOAA Tech. Rep. EDS 26, NOAA.

Davis, R. E., 1976: Predictability of Sea Surface Temperature and Sea Level Pressure anomalies over the North Pacific Ocean. $J$. Phys. Oceanogr., 6, 249-266.

Hamrick, A. M., and H. H. Martin, 1941: Fifty years' weather in Kansas, MO, 1889-1938. Mon. Wea. Rev., 44 (Suppl.), 53.

Karl, T. R., and C. N. Williams, Jr., 1987: An approach to adjusting climatological time series for discontinuous inhomogeneities. $J$. Climate Appl. Meteor., 27, 1744.

- - G. Kukla, and J. Gavin, 1984: Decreasing Diurnal Temperature Range in the United States and Canada from 1941 through 1980. J. Climate Appl. Meteor., 23, 950-966.

_- H. F. Diaz, and G. Kukla, 1988: Urbanization: Its detection and effect in the United States climate record. J. Climate, 1, 1099-1123.

—, C. N. William, Jr., P. J. Young, and W. Wendland, 1986: A model to estimate the time of observation bias associated with monthly mean maximum, minimum, and mean temperatures for the United States. J. Climate Appl. Meteor., 25, 145-160.

Livezey, R. E., and W. Y. Chen, 1983: Statistical field significance and its determination by Monte Carlo techniques. Mon. Wea. Rev., 111, 46-59.

Madden, R. A., and J. Williams, 1978: The correlation between temperature and precipitation in the United States and Europe. Mon. Wea. Rev., 106, 142-147.

Quinlan, F. T., T. R. Karl, and C. N. Williams, Jr., 1987: United States Historical Climatology Network (HCN) serial temperature and precipitation data. Rep. NDP-019, Carbon Dioxide Information Analysis Center, $33 \mathrm{pp}$.

Van den Dool, H. M., 1988: A utilitarian atlas of monthly and seasonal precipitation-temperature relations, the United States, 1931-1987. [Available from the Dept. Meteor., University of Maryland, College Park, MD 20742, SR-88-17.]

_- 1989: Monthly precipitation-temperature relations, the United States, 1931-1987. Proc,, 13th Annual Climate Diagnostics Workshop. Cambridge, U.S. Dept. of Commerce, 210-213.

Zhao, W., 1991: The relationship between precipitation and temperature over the continental United States. M.S. thesis, Global Change Research Center, Department of Environmental Science and Engineering, Oregon Graduate Institute of Science and Technology. 